\title{
28 Research Square \\ Comparisons of Five Equations Used for Estimating the Glomerular Filtrations Rate in Chinese Adults
}

shuai fu

Wuhan University Zhongnan Hospital https://orcid.org/0000-0003-1810-2876

Min Yang

Wuhan University Zhongnan Hospital

Si Xu

Wuhan University Zhongnan Hospital

Sha Wu

Wuhan University Zhongnan Hospital

Xiao Xiao

Wuhan University Zhongnan Hospital

Yugang $\mathrm{Hu}$

Wuhan University Renmin Hospital

Xiaoning Li ( $\nabla$ xiliusa2000@126.com)

https://orcid.org/0000-0002-0547-9116

\section{Research article}

Keywords: Glomerular filtration rate, Equation, Comparison, Creatinine, Cystatin C, Chinese

Posted Date: March 18th, 2020

DOI: https://doi.org/10.21203/rs.3.rs-17896/v1

License: (c) (i) This work is licensed under a Creative Commons Attribution 4.0 International License. Read Full License 


\section{Abstract}

Background

We aimed to assess the performance of revised MDRD, CKD-EPI, BIS, FAS and XiangYa equation in Chinese adults Methods

We collected blood biochemical data of 623 chinese adult hospitalised patients within 48 hours before they underwent 99m Tc-DTPA GFR measurement. We computed the bias (mGFR-eGFR), the precision (IQR), the accuray (P30囚and root mean square error (RMSE) relative to MGFR of each equation to evaluate performance. The ROC curves, Kappa value of McNemar test, Bland-Altman plot and the Intraclass correlation coefficient (ICC) were used to evaluate diagnostic accuracy and concordance.

Results

Totally, the FAS combined Scr and cysC equation performed supreme accuracy $(\mathrm{P} 30=57.5 \%, \mathrm{RMSE}=19.26)$, the cysC-based equation performed superior to Scr-based equation. Detailed P30 of the CKD-EPI cysC, FAS cysC , MDRD, CKD-EPI Scr-cysC, CKD-EPI Scr , FAS Scr , XiangYa was 56.7\%, 56.0\%, 53.5\%, 52.2\%, 48.8\%, 51.4\%, 43.0\%. The CKD-EPI cysC equation showed the lowest bias and the highest accuracy (bias=-2.23, P30 $=57.4 \%$ ) in $\mathrm{GFR}<60 \mathrm{ml} / \mathrm{min} / 1.73 \mathrm{~m} 2$, followed by the FASscr-cysC equation(bias=-6.89, P30 $=55.4 \%$ ). The XiangYa equation perfomed best in GFR $\geq 60 \mathrm{ml} / \mathrm{min} / 1.73 \mathrm{~m} 2$ while worst in GFR $<60 \mathrm{ml} / \mathrm{min} / 1.73 \mathrm{~m} 2$ with bias(-5.79 vs -19.05$)$, IQR(18.21 vs 10.85), P30(86.2\% vs $21.1 \%$ ), RMSE(16.68 vs 21.34). The CKD-EPI cysC equation had the lowest bias and the best accuracy (bias $=-2.23, \mathrm{P} 30=59.4 \%$ ) in age $\geq 70$ years adults, followed by the FAS Scr-cysC equation equivalented to BIS-2 Scr-cysC equation(bias -5.33 vs -4.90 , P30 $=57.3 \%$ ), while the XiangYa equation performed worstly (bias $=-20.39, \mathrm{P} 30=26.6 \%$ ). Best ROC AUC was gaven by the FAS Scr-cysC equation(0.951),so was it had the highest Kappa value(0.364). The lowest Bias showed in Bland-Altman plot was the CKD-EPI cysC equation(bias=7.46). The highest ICC value was gaven by the FAS Scr-cysC equation(0.921). Secondly, it was the XiangYa equation with the ICC of 0.912 .

\section{Conclusions}

The FAS Scr-cysC equation is verified most suitable and simpler applied to Chinese population. The CKD-EPI cysC equation is appropriate used in moderately and severely injured GFR(CKD3-5stage) and Seniors over 70 years old. The XiangYa equation performed perfectly in slightly injured GFR (CKD1-2stage), while further verification of XiangYa equation in multiple region need to carried out especially in moderately and severely injured GFR and older adults.

\section{Introduction}

Chronic kidney disease (CKD) is a global medical problem with a high incidence that affects a large proportion of the world's population[1]. The current prevalence of CKD is approximately $13.4 \%$ according to a global systematic review[2]. However, the prevalence of CKD varies widely both within and between countries. On the one hand, there are indeed regional differences in the prevalence of CKD. On the other hand, the diagnosis of CKD using eGFR, the different GFR thresholds for CKD in the elderly, and the use of one-time testing for eGFR or urine protein results to evaluate CKD all lead to different prevalence rates in large-scale epidemiological studies[3]. Population-based studies indicate that CKD epidemiology differs by sex, affecting more women than men, especially with regard to 
stage G3 CKD. The difference in CKD epidemiology by sex may be due to the natural decline in glomerular filtration rate (GFR) with age, as well as the potential overdiagnosis of CKD through the inappropriate use of GFR equations[4]. Thus, quick and accurate assessment of GFR is important for classifying the stage of chronic kidney disease because it can help assess the patient's current renal function, determine the dose of clinical drugs, and improve judgements regarding the reasonable timing of kidney dialysis or transplantation.

Presently, technetium-99m-diethylenetriaminepentaacetic acid ( ${ }^{99 m}$ Tc-DTPA) renal dynamic imaging is recommended for the measurement of GFR by the Nephrology Committee of the Society of Nuclear Medicine[5] and has been widely accepted as the standard value of GFR in clinical practice[6]. The calculation of the glomerular filtration rate in clinical practice mainly relies on the renal biomarkers serum creatinine (Scr) and serum cystatin $\mathrm{C}$ (ScysC). Several studies have shown that ScysC is a better marker than Scr[7-9] and is less affected by muscle mass and nutritional status. Current research confirms that within-subject variability in estimated GFR was lower than measured GFR, which indicates that estimates of GFR are at least as reliable as measured GFR for monitoring patients over time[10]. According to the epidemiology of mGFR in China, China has a large population base, with obvious differences in sex, region and race compared to these parameters in white people[11]. Therefore, it is necessary to evaluate the appropriate GFR equation for the Chinese population.

Since the traditional Cockcroft-Gault (CG) equation was widely applied in clinical practice in 1969, the exploration and correction of formulas are progressing consistently. With the standardization of the creatinine and cystatin $\mathrm{C}$ determination methods[12,13], the traditional calculation formula is obviously not applicable in the current clinical setting, so the Revised Modification of Diet in Renal Disease (MDRD) equation has emerged, incorporating standard creatinine measured by Roche enzyme assay dating back to isotope dilution mass spectrometry (IDMS) calibration[14]. The 2012 KDIGO guidelines recommend Scr-based and ScysC-based equations and the combined creatinine-cystatin C Chronic Kidney Disease Epidemiology Collaboration (CKD-EPI) equation used to calculate eGFR for adults[15]. Subsequently, correction can be performed according to Asian race[16].

Since the establishment of the guideline recommendations, there has been progress in the exploration of formulas in recent years, including the Berlin Initiative Study (BIS) equation for people over 70[17], the full age spectrum (FAS) equation[18, 19] (calibrated in Korea[20]), and the latest XiangYa equation based on the Chinese population[21]. At present, the applicability of various equations in Chinese adults still needs to be verified by a large multicentre population study. The purpose of this study is to compare the applicability of current authoritative and popular equations in the population in central China.

\section{Methods}

\section{Study population}

We performed a retrospective study by reviewing the electronic medical records of inpatients from June 2017 to July 2019 at Zhongnan Hospital of Wuhan University (Wuhan, China). The inclusion criteria were as follow: $邓$ patients who underwent GFR measurement using ${ }^{99 m}$ Tc-DTPA; 『age $\geq 18$ years; and $\nabla$ Scr and ScysC concentrations measured within 48 hours before the time measuring ${ }^{99 m}$ Tc-DTPA mGFR. We exclude the participants with acute renal failure, severe heart disease, pleural or abdominal effusion, renal stenosis, urinary obstruction, kidney tumour, severe malnutrition, physical disabilities, during pregnancy or lactation and patients who were taking trimethoprim, cimetidine, cefoxitin or underwent hemodialysis previously. Among the initial 681 selected inpatients, 19 had incomplete data for mGFR(unilateral renal insufficiency or without surface area 
calibration), 17 lacked ScysC concentration, 14 lacked Scr concentration $\llbracket$ measured by Jaffe’s alkaline picrate

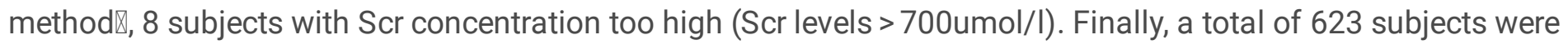
included in the study. The detailed characteristics of the study subjects are presented in Table 2.

Table 2

The Characteristics of the study population

\begin{tabular}{|c|c|c|c|}
\hline Characteristic & All subjects & Age $<70$ years & Age $\geq 70$ years \\
\hline 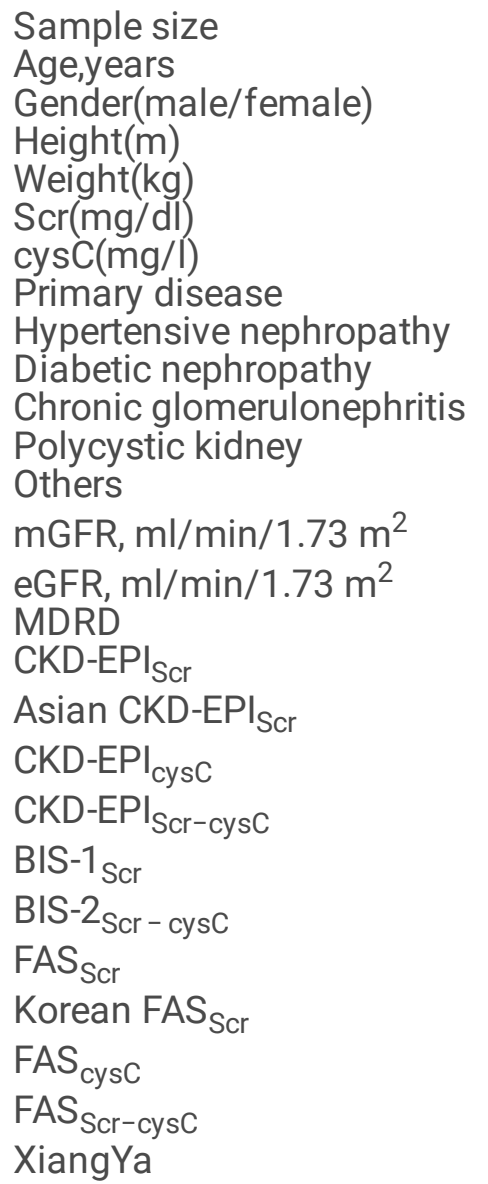 & $\begin{array}{l}623 \\
56.89(16.07) \\
383 / 240 \\
166.13(7.37) \\
66.09(11.54) \\
1.75(1.46) \\
1.74(1.06) \\
188(30.2 \%) \\
95(15.2 \%) \\
209(33.5 \%) \\
1(2 \%) \\
130(20.9 \%) \\
49.31(26.13) \\
61.53(37.86) \\
62.35(35.30) \\
65.59(37.13) \\
56.77(36.11) \\
60.79(38.79) \\
-- \\
-- \\
62.91(36.29) \\
63.64(37.19) \\
59.14(35.83) \\
59.59(33.54) \\
63.73(21.87)\end{array}$ & $\begin{array}{l}480 \\
50.93(13.07) \\
297 / 183 \\
167.06(7.36) \\
66.90(11.71) \\
1.71(1.45) \\
1.65(1.05) \\
120(25.0 \%) \\
72(15.0 \%) \\
178(37.1 \%) \\
1(2 \%) \\
109(22.7 \%) \\
53.01(26.60) \\
65.12(39.37) \\
66.74(36.49) \\
70.21(38.38) \\
62.06(37.65) \\
66.10(40.57) \\
-- \\
-- \\
68.60(37.55) \\
69.54(38.54) \\
64.52(37.74) \\
65.03(34.89) \\
66.48(22.51)\end{array}$ & $\begin{array}{l}143 \\
76.92(5.54) \\
86 / 57 \\
162.97(6.55)^{\star \star} \\
63.35(10.55)^{\star \star} \\
1.87(1.48)^{\star} \\
2.01(1.04)^{\star \star} \\
68(47.6 \%) \\
23(16.1 \%) \\
31(21.7 \%) \\
0(0 \%) \\
21(14.7 \%) \\
36.86(20.03) \\
49.48(29.38)^{\star \star} \\
47.62(26.14)^{\star \star} \\
50.10(27.50)^{\star \star} \\
38.99(22.78)^{\star \star} \\
42.96(24.93)^{\star \star} \\
44.50(20.75)^{\star \star} \\
41.15(19.20)^{\star \star} \\
43.81(23.12)^{\star \star} \\
43.82(23.12)^{\star \star} \\
41.06(19.81)^{\star \star} \\
41.36(19.67)^{\star \star} \\
54.48(16.52)^{\star \star}\end{array}$ \\
\hline
\end{tabular}

\section{Laboratory assay}

We measured serum creatinine with use of Roche enzymatic method and IDMS calibration (Beckman AU5800 Coulter chemistry analyzers, Ltd, Tokyo, Japan), traceable to National Institute of Standards and technology(NIST) creatinine standard reference material(SRM 967)[13], with a reported coefficient of variation of 2.3\%(reference range:64-104umol/L). we measured serum cystatin $C$ with use of particle-enhanced nephelometric immunoassay(Beckman AU5800 Automatic biochemical analyzers, Ltd, Tokyo, Japan),traceable to international standards[22], with a reported coefficient of variation of $10 \%$ (reference range:0-1.2 mg/L). mGFR was measured by using the radioactive isotope ${ }^{99 m}$ Tc-DTPA, Patients were required to have an fasting state on the day of examination, empty the bladder, drink $500 \mathrm{ml}$ water within 30 minutes before examination, get a bolus injection of $5 \mathrm{mCi}{ }^{99 m}$ Tc-DTPA via the cubital vein projectile, We perform renal dynamic imaging by a single photon emission computed tomography (CT) scanner, and obtain standardized mGFR by Gates method[23] according to the patient's weight and height. 


\section{Calculation of eGFR}

The eGFR was calculated by using 2007MDRD, 2012CKD-EPI, 2012BIS, 2017FAS, 2018XiangYa equations, the detailed expressions are presented in Table 1.

Table 1

The expression of the eGFR cacularion equations

\begin{tabular}{|c|c|c|}
\hline Year & Name & Equation \\
\hline $\begin{array}{l}2007 \\
2009 \\
2011 \\
2012 \\
2012 \\
2016 \\
2017 \\
2018\end{array}$ & 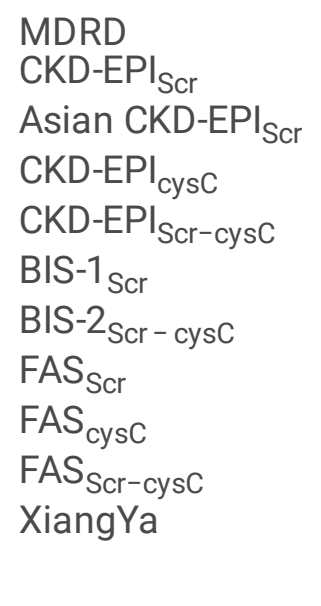 & 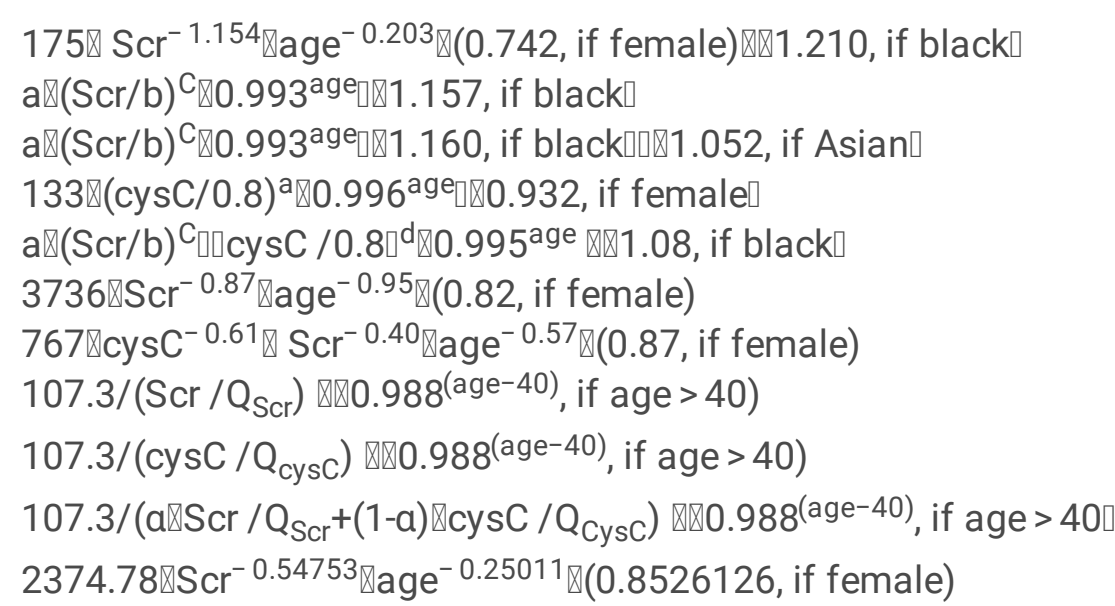 \\
\hline
\end{tabular}

eGFR was shown as $\mathrm{ml} / \mathrm{min} / 1.73 \mathrm{~m}^{2}$; Scr was shown as $\mathrm{mg} / \mathrm{dl}$ ( except in XiangYa equation shown as umol/l), to convert Scr from umol/l to $\mathrm{mg} / \mathrm{dl}$, divide by 88.4; cysC was shown as $\mathrm{mg} / \mathrm{l}$. For CKD-EPI $\mathrm{Scr}_{\mathrm{S}}$ and Asian CKD$\mathrm{EPI}_{\mathrm{Scr}}$ equation, $\mathrm{a}=141$, if male; $\mathrm{a}=144$, if female; $b=0.9$ if male; $b=0.7$, if female; $c=-0.411$, if male, $\mathrm{Scr} \leq$ $0.9 \mathrm{mg} / \mathrm{dl} ; \mathrm{c}=-1.209$, if male, $\mathrm{Scr}>0.9 \mathrm{mg} / \mathrm{dl} ; \mathrm{c}=-0.329$, if female, $\mathrm{Scr} \leq 0.7 \mathrm{mg} / \mathrm{dl} ; \mathrm{c}=-1.209$, if female, $\mathrm{Scr}>$

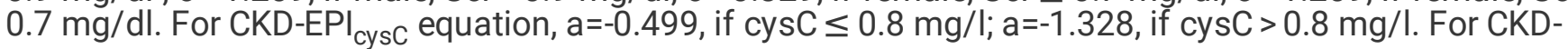
$E_{\text {Scr-cysc }}$ equation, $a=135$, if male; $a=130$, if female; $b=0.9$, if male; $b=0.7$, if female; $c=-0.207$, if male, $S c r \leq$ $0.9 \mathrm{mg} / \mathrm{dl}$; $\mathrm{c}=-0.061$, if male, $\mathrm{Scr}>0.9 \mathrm{mg} / \mathrm{dl} ; \mathrm{c}=-0.248$, if female, $\mathrm{Scr} \leq 0.7 \mathrm{mg} / \mathrm{dl} ; \mathrm{c}=-0.061$, if female, $\mathrm{Scr}>$ $0.7 \mathrm{mg} / \mathrm{dl}$. $\mathrm{d}=-0.375$, if cysC $\leq 0.8 \mathrm{mg} / \mathrm{l} ; \mathrm{d}=-0.711$, if cysC $>0.8 \mathrm{mg} / \mathrm{l}$. For FAS $\mathrm{Scr}_{\mathrm{S}}$ equation, $\mathrm{Q}_{\mathrm{Scr}}$ was the mean or median Scr value for age-/-specific healthy populations, matched with age or with median height obtained from Belgian national growth curves; $Q_{\mathrm{Scr}}=0.9 \mathrm{mg} / \mathrm{dl}$, if male; $Q_{\mathrm{Scr}}=0.7 \mathrm{mg} / \mathrm{dl}$, if female; But for Korean revised, $Q_{\mathrm{Scr}}$ $=0.96 \mathrm{mg} / \mathrm{dl}$, if male; $Q_{\text {scr }}=0.7 \mathrm{mg} / \mathrm{dl}$, if female. For $F A S_{\text {cysc }}$ equation, $Q_{\text {cysC }}=0.82 \mathrm{mg} / \mathrm{l}$, if age $<70 ; Q_{\text {cysC }}$ $=0.95 \mathrm{mg} / \mathrm{l}$, if age $\geq 70$. For $F A S_{\text {Scr-cysC }}$ equation, $a$ and $1-a$ are weighted by $S c r / Q_{S c r}$ and cysC $/ Q_{c y s c}, a=0.5$ in the study.

\section{Statistical analysis}

Continuous variables were performed as mean \pm standard(SD), categorical variables were performed as percentage(\%). Normally distributed groups of variables were computed with t-test, Skewed distributed variables were tested using nonparametric tests Wilcoxon and Mann-Whitney U, Categorical variables were computed with chi-square test, $\mathrm{P}<0.05$ were considered statistically significant. ${ }^{99 \mathrm{~m}}$ Tc-DTPA mGFR was taken as reference value of actual GFR, Bias was assessed as the median difference between mGFR and eGFR(mGFR-eGFR). Precision was assessed as the inter-quartile range(IQR) for the differences. Accuracy was assessed as root mean square error (RMSE) relative to mGFR and the percentage of eGFR deviating within $30 \%$ of mGFR(P30), which was proposed in $\mathrm{K} / \mathrm{DOQ}$ I clinical practice guideline[24]. Receiver-operating characteristic (ROC) curves were computed for CKD diagnosis according to mGFR and eGFR (CKD are diagnosed based on 2012 clinical practice guideline[15]). Concordance between mGFR and eGFR were compared using the Intraclass correlation coefficient (ICC). The BlandAltman plot analysis was used to calculate mean difference and precision between mGFR and eGFR. McNemar test 
and kappa value was used to assess the CKD stages agreement between mGFR and eGFR categories. Subgrouds were based on $\mathrm{mGFR}<60$ or $\geq 60 \mathrm{ml} / \mathrm{min} / 1.73 \mathrm{~m}^{2}$ and age $<70$ or $\geq 70$ years old. All statistical analysis were computed using SPSS software(version22.0; SPSS Chicago, IL, USA) and GraphPad Prism for Windows(version7.04; GraphPad software, San Diego, California, IL, USA).

\section{Results}

\section{Basic characteristics}

Of the 623 patients, 383 were male and 240 were female. The mean age was 56.89 years. There were 480 adults under 70 years old and 143 elderly people over 70 years old. The mean height and weight were 166.13 meters and $66.09 \mathrm{~kg}$. The average values of Scr and cysC were $1.75 \mathrm{mg} / \mathrm{dl}$ and $1.74 \mathrm{mg} / \mathrm{l}$, respectively. The primary cause of CKD was chronic glomerulonephritis (33.5\%), followed by hypertensive nephropathy (30.2\%) and diabetic nephropathy (15.2\%), which was consistent with the world epidemiological survey of chronic kidney disease[25]. In the elderly group over 70 years old, the most common primary disease was hypertensive nephropathy (47.6\%), followed by chronic nephritis (21.7\%) and diabetic nephropathy (16.1\%). The mean ${ }^{99 \mathrm{~m}} \mathrm{Tc}-\mathrm{DTPA}$ mGFR was $49.31 \mathrm{ml} / \mathrm{min} / 1.73 \mathrm{~m}^{2}$, and it was $53.01 \mathrm{ml} / \mathrm{min} / 1.73 \mathrm{~m}^{2}$ in adults under 70 years old and $36.86 \mathrm{ml} / \mathrm{min} / 1.73 \mathrm{~m}$ in the elderly population over 70 .

\section{Performance results of different equations in all subjects}

The bias, precision and accuracy of each eGFR equation computed for all subjects are shown in Table 3. All equations were compared with the $\mathrm{CKD}^{-\mathrm{EPI}_{\mathrm{Scr}}}$ equation. Regarding the equation based on only the Scr concentration, the MDRD equation performed superior to the others, with the lowest bias (-8.53), relatively lower precision (IQR of 21.99), and the highest accuracy (P30 of 53.5\%) but was not significantly different from the

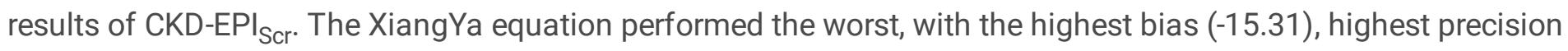
(IQR of 14.92), and lowest accuracy (P30 of 43.0\%). The equation based on only cysC performed integrally superior

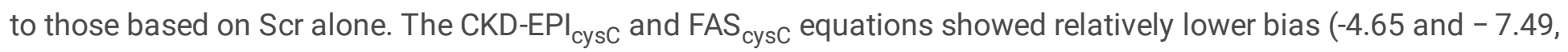
respectively), moderate precision (IQR of 21.97 and 18.41, respectively), and higher accuracy (P30 of $56.7 \%$ and

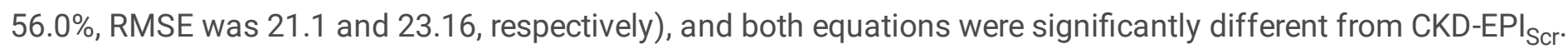

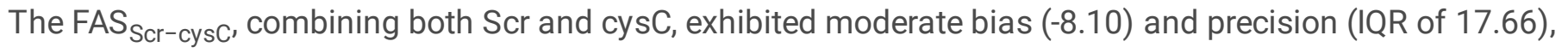
supreme accuracy (P30 reached 57.5\%, RMSE was 19.26), and significantly higher performance than the CKD$\mathrm{EPI}_{\text {Scr-cysC }}$ equation (P30 of 52.2\%). Generally, the FAS equation based on the combination of Scr and cysC performed better than the other equations, and the cysC-based equation showed higher accuracy than the Scrbased equation. 
Table 3

The performance of the eGFR equations in all subjects

\begin{tabular}{|c|c|c|c|c|}
\hline & \multirow{2}{*}{$\begin{array}{l}\text { Bias } \\
\text { Median difference }\end{array}$} & \multirow{2}{*}{$\begin{array}{l}\text { Precision } \\
\text { IQR of the difference }\end{array}$} & \multicolumn{2}{|c|}{ Accuracy } \\
\hline & & & P30 & RMSE \\
\hline $\begin{array}{l}\text { All subjects } \\
\text { MDRD } \\
\text { CKD-EPI }_{\text {Scr }} \\
\text { Asian CKD-EPI }_{\text {Scr }} \\
\text { CKD-EPI }_{\text {cysC }} \\
\text { CKD-EPI }_{\text {Scr-cysC }} \\
\text { FAS }_{\text {Scr }} \\
\text { Korean FAS }_{\text {Scr }} \\
\text { FAS }_{\text {cysC }} \\
\text { FAS Scr-cysC }_{\text {XiangYa }}\end{array}$ & $\begin{array}{l}-8.53^{\star \star} \\
-10.67 \\
-13.88^{\star \star} \\
-4.65^{\star \star} \\
-7.39^{\star *} \\
-10.16 \\
-10.37^{\star} \\
-7.49^{\star *} \\
-8.10^{\star \star} \\
-15.31^{\star}\end{array}$ & $\begin{array}{l}21.99 \\
24.83 \\
27.71 \\
21.97 \\
25.09 \\
20.51 \\
21.38 \\
18.41 \\
17.66 \\
14.92\end{array}$ & $\begin{array}{l}53.5 \% \\
48.8 \% \\
42.9 \%^{\star} \\
56.7 \%^{\star \star} \\
52.2 \% \\
51.4 \% \\
50.4 \%^{*} \\
56.0 \%^{\star} \\
57.5 \%^{\star \star} \\
43.0 \%^{\star}\end{array}$ & $\begin{array}{l}25.09 \\
22.40 \\
25.43 \\
21.11 \\
23.10 \\
23.82 \\
24.88 \\
23.16 \\
19.26 \\
19.89\end{array}$ \\
\hline
\end{tabular}

\section{Performance results of different equations in subgroups}

The performance of each eGFR equation in the CKD subgroups and age subgroups is shown in Tables 4 and 5 . $\mathrm{mGFR} \geq 60 \mathrm{ml} / \mathrm{min} / 1.73 \mathrm{~m}^{2}$ was defined as slightly reduced GFR, and $\mathrm{mGFR}<60 \mathrm{ml} / \mathrm{min} / 1.73 \mathrm{~m}^{2}$ was defined as moderately-to-severely reduced GFR. The results of the subgroup analyses differed from the results of all subjects. In subgroups with $\mathrm{mGFR} \geq 60 \mathrm{ml} / \mathrm{min} / 1.73 \mathrm{~m}^{2}$, the XiangYa equation showed the lowest bias (-5.79), highest precision (IQR of 18.21) and the highest accuracy (P30 of 86.2\%, RMSE was 16.68), which met the criterion of P30 $\geq 75 \%$ established in the $2002 \mathrm{~K} / \mathrm{DOQ}$ I clinical practice guidelines[24]. The equation with the second best performance was the $\mathrm{FAS}_{\mathrm{cysC}}$ equation (bias of -10.49 , P30 of $61.9 \%$ ), followed by the $\mathrm{FAS}_{\mathrm{Scr}-\mathrm{cysC}}$ equation, which performed equivalent to the MDRD equation (bias of -16.16 and -16.62 , P30 of $61.4 \%$ ). However, in the subgroups with $\mathrm{mGFR}<60 \mathrm{ml} / \mathrm{min} / 1.73 \mathrm{~m}^{2}$, the XiangYa equation had the worst performance, with the highest bias (-19.05),

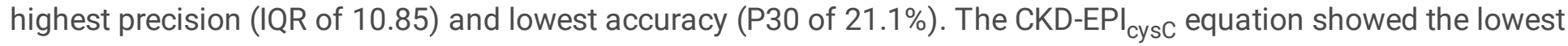

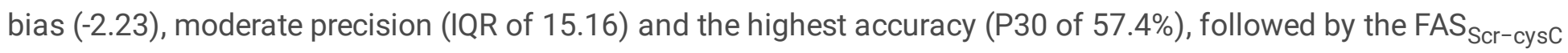
equation (P30 of 55.4\%). All of the equations were significantly associated with the $\mathrm{CKD}-\mathrm{EPI} \mathrm{Scr}_{\mathrm{S}}$ equation. 
Table 4

The performance of the eGFR equations in mGFR subgroups

\begin{tabular}{|c|c|c|c|c|}
\hline & Bias & Precision & \multicolumn{2}{|l|}{ Accuracy } \\
\hline & Median difference & IQR of the difference & P30 & RMSE \\
\hline \multicolumn{5}{|c|}{$\mathrm{mGFR} \geq 60 \mathrm{ml} / \mathrm{min} / 1.73 \mathrm{~m}^{2}$} \\
\hline $\begin{array}{l}\text { MDRD } \\
\text { CKD-EPI }_{\text {Scr }} \\
\text { Asian CKD-EPI }_{\text {Scr }} \\
\text { CKD-EPI }_{\text {cysC }} \\
\text { CKD-EPI }_{\text {Scr-cysC }} \\
\text { FAS }_{\text {Scr }} \\
\text { Korean FAS }_{\text {Scr }} \\
\text { FAS }_{\text {cysC }} \\
\text { FAS Scr-cysC }_{\text {XiangYa }}\end{array}$ & $\begin{array}{l}-16.62^{\star \star} \\
-19.55 \\
-24.68^{\star \star} \\
-15.84^{\star} \\
-22.77^{\star \star} \\
-18.63 \\
-19.82 \\
-10.49^{\star \star} \\
-16.16^{\star \star} \\
-5.79^{\star \star}\end{array}$ & $\begin{array}{l}25.76 \\
23.78 \\
23.63 \\
36.17 \\
32.29 \\
25.17 \\
25.51 \\
33.95 \\
27.21 \\
18.21\end{array}$ & $\begin{array}{l}61.4 \% \\
55.2 \% \\
44.8 \%{ }^{\star} \\
55.2 \% \\
48.1 \% \\
57.6 \% \\
54.8 \% \\
61.9 \% \\
61.4 \% \\
86.2 \% \text { ** }\end{array}$ & $\begin{array}{l}33.31 \\
26.57 \\
30.79 \\
29.71 \\
33.68 \\
32.24 \\
34.01 \\
34.43 \\
27.27 \\
16.68\end{array}$ \\
\hline \multicolumn{5}{|c|}{$\mathrm{mGFR}<60 \mathrm{ml} / \mathrm{min} / 1.73 \mathrm{~m}^{2}$} \\
\hline $\begin{array}{l}\text { MDRD } \\
\text { CKD-EPI }_{\text {Scr }} \\
\text { Asian CKD-EPI }_{\text {Scr }} \\
\text { CKD-EPI }_{\text {cysC }} \\
\text { CKD-EPI }_{\text {Scr-cysC }} \\
\text { FAS }_{\text {Scr }} \\
\text { Korean FAS }_{\text {Scr }} \\
\text { FAS }_{\text {cysC }} \\
\text { FAS }_{\text {Scr-cysC }} \\
\text { XiangYa }\end{array}$ & $\begin{array}{l}-5.31^{\star \star} \\
-7.14 \\
-9.21^{\star \star} \\
-2.23^{\star \star} \\
-3.38^{\star \star} \\
-7.14 \\
-7.14^{\star} \\
-6.69^{\star} \\
-6.89^{\star} \\
-19.05^{\star \star}\end{array}$ & $\begin{array}{l}18.59 \\
21.20 \\
23.16 \\
15.16 \\
16.27 \\
16.05 \\
16.02 \\
14.49 \\
13.36 \\
10.85\end{array}$ & $\begin{array}{l}49.4 \% \\
45.5 \% \\
41.9 \% \\
57.4 \% * \\
54.2 \% \\
48.2 \% \\
48.2 \% \\
53.0 \% \text { * } \\
55.4 \% \text { ** } \\
21.1 \% \text { ** }\end{array}$ & $\begin{array}{l}19.63 \\
19.94 \\
22.21 \\
14.94 \\
15.10 \\
18.09 \\
18.59 \\
14.36 \\
13.46 \\
21.34\end{array}$ \\
\hline $\begin{array}{l}\text { Bias was median } \\
\text { was the proportior } \\
\star \star P<0.01 \text {, compa }\end{array}$ & $\begin{array}{l}\text { ce between mGFR an } \\
\text { R within } 30 \% \text { of mGF } \\
\text { CKD-EPI }\end{array}$ & $\begin{array}{l}\text { IQR was the inter-qua } \\
\text { E was root mean squa }\end{array}$ & $\begin{array}{l}\text { of the dif } \\
\text { ative to } \mathrm{n}\end{array}$ & $\begin{array}{l}\text { ce; } P 30 \\
* P<0.05\end{array}$ \\
\hline
\end{tabular}


Table 5

The performance of the eGFR equations in age subgroups

\begin{tabular}{|c|c|c|c|c|}
\hline & Bias & Precision & \multicolumn{2}{|l|}{ Accuracy } \\
\hline & Median difference & IQR of the difference & P30 & RMSE \\
\hline \multicolumn{5}{|l|}{ Age $<70$ years } \\
\hline $\begin{array}{l}\text { MDRD } \\
\text { CKD-EPI }_{\text {Scr }} \\
\text { Asian CKD-EPI }_{\text {Scr }} \\
\text { CKD-EPI }_{\text {cysC }} \\
\text { CKD-EPI }_{\text {Scr-cysC }} \\
\text { FAS }_{\text {Scr }} \\
\text { Korean FAS }_{\text {Scr }} \\
\text { FAS }_{\text {cysC }} \\
\text { FAS Scr-cysC }_{\text {XiangYa }}\end{array}$ & $\begin{array}{l}-7.99^{\star *} \\
-11.36 \\
-15.25^{\star \star} \\
-5.69^{\star *} \\
-8.86^{\star} \\
-12.00^{\star \star} \\
-12.87^{\star \star} \\
-8.12^{\star \star} \\
-9.43^{\star} \\
-14.71\end{array}$ & $\begin{array}{l}23.15 \\
25.79 \\
29.61 \\
24.76 \\
29.19 \\
21.54 \\
22.78 \\
20.24 \\
20.27 \\
14.84\end{array}$ & $\begin{array}{l}57.9 \% * \\
51.0 \% \\
43.8 \% * \\
55.8 \% \\
51.9 \% \\
51.5 \% \\
50.2 \% \\
56.7 \% \\
57.5 \% * \\
47.9 \%\end{array}$ & $\begin{array}{l}25.13 \\
22.81 \\
26.09 \\
22.44 \\
24.59 \\
25.22 \\
26.51 \\
25.05 \\
20.55 \\
18.96\end{array}$ \\
\hline \multicolumn{5}{|l|}{ Age $\geq 70$ years } \\
\hline $\begin{array}{l}\text { MDRD }_{\text {CKD-EPI }_{\text {Scr }}} \\
\text { Asian CKD-EPI }_{\text {Scr }} \\
\text { CKD-EPI }_{\text {cysC }} \\
\text { CKD-EPI }_{\text {Scr-cysC }} \\
\text { BIS-1 }_{\text {Scr }} \\
\text { BIS-2 }_{\text {Scr-cysC }} \\
\text { FAS }_{\text {Scr }} \\
\text { Korean FAS }_{\text {Scr }} \\
\text { FAS }_{\text {cysC }} \\
\text { FAS }_{\text {Scr-cysC }} \\
\text { XiangYa }\end{array}$ & $\begin{array}{l}-10.23^{\star \star} \\
-9.13^{-11.30 \star \star} \\
-2.23^{\star \star} \\
-4.86^{\star \star} \\
-8.05^{\star \star} \\
-4.90^{\star \star} \\
-6.12^{\star \star} \\
-6.12^{\star \star} \\
-5.78^{\star \star} \\
-5.33^{\star \star} \\
-20.39^{\star \star}\end{array}$ & $\begin{array}{l}19.96 \\
20.47 \\
22.60 \\
13.21 \\
14.49 \\
13.38 \\
12.98 \\
14.06 \\
14.06 \\
14.27 \\
13.25 \\
14.75\end{array}$ & $\begin{array}{l}38.5 \% \\
41.3 \% \\
39.9 \% \\
59.4 \% \star \star \\
53.1 \% \star \\
48.3 \% \\
57.3 \% \text { } \\
51.0 \% \\
51.0 \% \\
53.8 \% \star \\
57.3 \% \star \star \\
26.6 \% \text { ** }\end{array}$ & $\begin{array}{l}24.96 \\
20.97 \\
23.07 \\
15.83 \\
17.17 \\
17.27 \\
14.05 \\
18.34 \\
18.34 \\
15.14 \\
14.08 \\
22.75\end{array}$ \\
\hline
\end{tabular}

In the subgroups of adults aged $<70$ years, the MDRD equation performed almost equivalent to the FAS Scr-cysC equation (P30 of $57.9 \%$ and 57.5\%, respectively); however, the MDRD equation had lower bias (-7.99 and - 9.43, respectively) and lower precision (IQR of 23.15 and 20.27, respectively). Both equations were significantly associated with the $\mathrm{CKD}-\mathrm{EPI}_{\mathrm{Scr}}$ equation. In older adults aged $\geq 70$ years, the $\mathrm{CKD}-\mathrm{EPI}_{\mathrm{cysC}}$ had the lowest bias (-2.23), relatively higher precision (IQR of 13.21) and the best accuracy (P30 of 59.4\%). The FAS Scr-cysC $_{\text {equation }}$

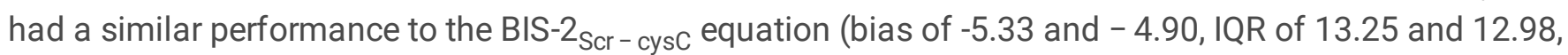
respectively; P30 of 57.3). The XiangYa equation had the worst performance, with the highest bias (-20.39), moderate precision (IQR of 14.75) and the lowest accuracy (P30 of 26.6\%). These four equations mentioned above were significantly associated with the CKD-EPI ${ }_{S c r}$ equation.

\section{Comparison between mGFR and eGFR}


The CKD stage diagnostic accuracy of eGFR equations and the ICC values between mGFR and eGFR are shown in Table 6. CKD was defined by $\mathrm{mGFR}<60 \mathrm{ml} / \mathrm{min} / 1.73 \mathrm{~m}^{2}$, and CKD stage was divided according to the 2012 clinical practice guidelines. The ROC curves of the main equations, including the $\mathrm{FAS}_{\mathrm{Scr}-\mathrm{cysC}}, \mathrm{CKD}-\mathrm{EPI}_{\mathrm{cysC}}, \mathrm{XiangYa}_{\mathrm{a}}$ and

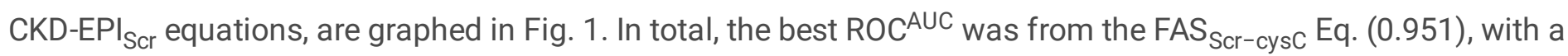
sensitivity of $88.57 \%$ and specificity of $87.65 \%$. Next, was CKD-EPI Scr-cysC $_{\text {( }}(0.950)$, with a sensitivity of $85.71 \%$ and a specificity of $88.62 \%$. Nevertheless, the MDRD equation had the lowest ROCAUC $(0.925)$. For the division concordance of CKD stages, the $\mathrm{FAS}_{\mathrm{Scr}-\mathrm{cysC}}$ equation had the highest kappa value (0.364), followed by the CKD$\mathrm{EPI}_{\text {Scr-cysC }}$ Eq. (0.345). The concordance between the mGFR and each eGFR was graphed as a Bland-Altman plot, as shown in Fig. 2. The CKD-EPI ${ }_{\text {cysc }}, F_{\text {AS }} S_{\text {cys }}$ and $\mathrm{FAS}_{\mathrm{Scr}-\mathrm{cysC}}$ equations showed relatively higher concordance with mGFR, as the mean bias between them was $7.46,9.84$, and $10.29 \mathrm{ml} / \mathrm{min} / 1.73 \mathrm{~m}^{2}$, respectively. In addition, the BIS$2_{\text {Scr-cysC }}$ equation showed higher concordance than the BIS-1 ${ }_{\text {Scr }}$ equation with a lower bias of $4.30 \mathrm{ml} / \mathrm{min} / 1.73 \mathrm{~m}^{2}$. The highest ICC value was obtained by the FAS Scr-cysC $_{\text {Eq. }}(0.921)$. Second, the XiangYa equation had an ICC of 0.912 . These two eGFR equations showed very good correlation with mGFR, with an ICC > 0.91 . 
Table 6

The concordance and diagnostic accuracy between mGFR and eGFR

\begin{tabular}{|c|c|c|c|c|c|c|c|c|c|c|c|}
\hline \multirow[t]{2}{*}{ Equation } & \multicolumn{6}{|c|}{ CKD stages } & \multirow[t]{2}{*}{ ROCAUC } & \multirow[t]{2}{*}{ Sensitvity } & \multirow[t]{2}{*}{ Specificity } & \multirow[t]{2}{*}{ kappa } & \multirow[t]{2}{*}{ ICC } \\
\hline & 1 & 2 & $3 a$ & $3 b$ & 4 & 5 & & & & & \\
\hline \multicolumn{12}{|l|}{ All subject } \\
\hline 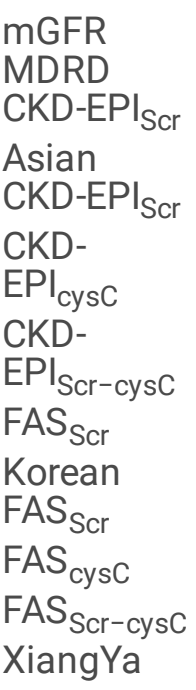 & $\begin{array}{l}53 \\
128 \\
171 \\
195 \\
134 \\
153 \\
148 \\
154 \\
107 \\
127 \\
68\end{array}$ & $\begin{array}{l}157 \\
177 \\
149 \\
135 \\
127 \\
137 \\
157 \\
151 \\
150 \\
142 \\
279\end{array}$ & $\begin{array}{l}114 \\
80 \\
75 \\
75 \\
68 \\
71 \\
86 \\
87 \\
94 \\
99 \\
137\end{array}$ & $\begin{array}{l}124 \\
86 \\
78 \\
76 \\
104 \\
92 \\
92 \\
94 \\
136 \\
111 \\
101\end{array}$ & $\begin{array}{l}123 \\
92 \\
90 \\
85 \\
133 \\
108 \\
100 \\
97 \\
123 \\
113 \\
38\end{array}$ & $\begin{array}{l}52 \\
60 \\
60 \\
57 \\
57 \\
62 \\
40 \\
40 \\
13 \\
31 \\
0\end{array}$ & $\begin{array}{l}0.925^{\star \star} \\
0.935^{\star \star} \\
0.935^{\star \star} \\
0.938^{\star \star} \\
0.950^{\star \star} \\
0.936^{\star \star} \\
0.935^{\star \star} \\
0.937^{\star \star} \\
0.951^{\star \star} \\
0.930^{\star \star}\end{array}$ & $\begin{array}{l}84.19 \\
82.86 \\
82.86 \\
88.10 \\
85.71 \\
89.52 \\
90.00 \\
92.38 \\
88.57 \\
87.14\end{array}$ & $\begin{array}{l}82.26 \\
89.35 \\
89.35 \\
83.78 \\
88.62 \\
82.57 \\
82.32 \\
80.87 \\
87.65 \\
84.02\end{array}$ & $\begin{array}{l}0.333^{\star \star} \\
0.264^{\star \star} \\
0.243^{\star \star} \\
0.331^{\star \star} \\
0.345^{\star \star} \\
0.301^{\star \star} \\
0.291^{\star \star} \\
0.315^{\star \star} \\
0.364^{\star \star} \\
0.126^{\star \star}\end{array}$ & $\begin{array}{l}0.872 \\
0.906 \\
0.898 \\
0.891 \\
0.899 \\
0.894 \\
0.889 \\
0.874 \\
0.921 \\
0.912\end{array}$ \\
\hline \multicolumn{12}{|c|}{ Age $\geq 70$ years } \\
\hline $\begin{array}{l}\text { mGFR } \\
\text { BIS-1 } \\
\text { BIS-2 } \\
\text { cysc }\end{array}$ & $\begin{array}{l}3 \\
2 \\
1\end{array}$ & $\begin{array}{l}13 \\
35 \\
25\end{array}$ & $\begin{array}{l}27 \\
33 \\
33\end{array}$ & $\begin{array}{l}39 \\
34 \\
34\end{array}$ & $\begin{array}{l}44 \\
28 \\
38\end{array}$ & $\begin{array}{l}17 \\
11 \\
12\end{array}$ & $\begin{array}{l}0.828 * \star \\
0.870^{\star \star}\end{array}$ & $\begin{array}{l}87.50 \\
87.50\end{array}$ & $\begin{array}{l}75.59 \\
74.80\end{array}$ & $\begin{array}{l}0.248^{\star \star} \\
0.322^{\star \star}\end{array}$ & $\begin{array}{l}0.830 \\
0.867\end{array}$ \\
\hline \multicolumn{12}{|c|}{$\begin{array}{l}\text { *P }<0.05, * * P<0.01 \text {, equations were compared with } \mathrm{mGFR} \text { in all subjects except for } \mathrm{BIS} \text { equations used in older } \\
\text { people age } \geq 70 \text { year old; Kappa was } \mathrm{K} \text { interpretation; } 0.81-1 \text { almost perfect(very good); } 0.61-0.80 \\
\text { substantial(good); } 0.41-0.60 \text { moderate; } 0.21-0.40 \text { fair; } 0.00-0.20 \text { sight; }<0.00 \text { poor; }\end{array}$} \\
\hline $\begin{array}{l}\text { ICC was int } \\
\text { good correl } \\
\text { ICC }<0.31 \mathrm{~s}\end{array}$ & $\begin{array}{l}\text { ass } \\
\text { h; } 0 . \\
\text { ed v }\end{array}$ & $\begin{array}{l}\text { relat } \\
<\text { ICC } \\
\text { bac }\end{array}$ & $\begin{array}{l}\text { coe } \\
0.71 \\
\text { orrela }\end{array}$ & $\begin{array}{l}\text { ient; } \\
\text { owec } \\
\text { on }\end{array}$ & $>$ & sh & $\begin{array}{l}\text { ed very } \\
\text { lation; }\end{array}$ & $\begin{array}{l}\text { od correla } \\
1<\text { ICC }<0 .\end{array}$ & $\begin{array}{l}\mathrm{n} ; 0.71<\mathrm{ICC} \\
\text { showed bad }\end{array}$ & $\begin{array}{l}0.91 \text { sho } \\
\text { orrelatic }\end{array}$ & $\begin{array}{l}\text { ed } \\
\text { and }\end{array}$ \\
\hline
\end{tabular}

\section{Discussion}

We have been committed to evaluating the most accurate and clinically practical equation for the Chinese population out of the internationally popular GFR estimation equations in recent years. The results of our study

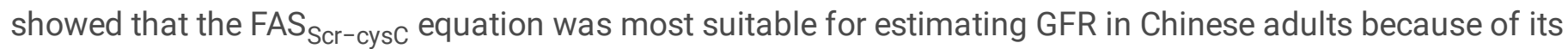
superior accuracy (P30 of 57.5\%), excellent concordance with mGFR (ICC of 0.921) and good diagnostic accuracy (ROCAUC of 0.951, Kappa value was 0.364) for all subjects. Moreover, its advantage that it can be used for the full age spectrum increases its clinical practicality. However, we still found that the CKD-EPI ${ }_{\text {cysc }}$ equation had advantages when applied to individuals with moderately and severely reduced GFR (GFR $\left.<60 \mathrm{ml} / \mathrm{min} / 1.73 \mathrm{~m}^{2}\right)$ and adults over 70 years, as its low bias (-2.23), high accuracy (57.4\% and 59.4\%), and lowest mean bias (7.46) were shown in Bland-Altman plots. Otherwise, the XiangYa equation was confirmed to be appropriate for individuals with 
slightly reduced GFR (GFR $\geq 60 \mathrm{ml} / \mathrm{min} / 1.73 \mathrm{~m}^{2}$ ) due to its low bias (-5.79), high precision (18.21), high accuracy (86.2\%), and very good concordance with mGFR (ICC of 0.912 ).

The FAS equation was developed on the basis of the average GFR of the human body before the age of 40 being approximately $107.3 \mathrm{ml} / \mathrm{min} / 1.73 \mathrm{~m}^{2}$. After 40 years of age, the GFR decreases at the level of $1 \mathrm{ml} / \mathrm{min} / 1.73 \mathrm{~m}{ }^{2}$ per year, and the rate of decline is approximately $0.988[26]$. Chai $L$ et al performed the first study to suggest the

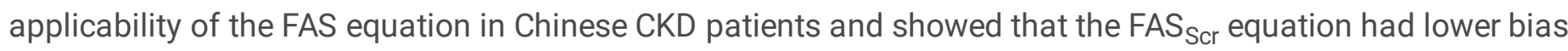
(1.28) and higher accuracy (P30 of 63.64, RMSE was 19.49 in adults under 70 years and 14.06 in elderly individuals over 70 years) than the CKD-EPI equation or the MDRD equation in a single-centre study of 396 subjects in eastern China [27]. Another single-centre study of 162 subjects conducted by Xie P et al in northern China found that the $\mathrm{FAS}_{\mathrm{Scr}}$ equation had excellent concordance with the result measured by the ${ }^{99 \mathrm{~m}} \mathrm{Tc}$-DTPA dual plasma sample clearance method (mGFR $=-0.374+1.029$ eGFR $(p<0001)$ ), even performing better than the results measured by the ${ }^{99 \mathrm{~m}}$ Tc-DTPA renal dynamic imaging method (bias-1.22 vs 8.92, precision 15.69 vs 18.36 , P30 $75.31 \%$ vs $59.26 \%$ ) [28]. A Korean study by Jeong TD et al compared the $\mathrm{FAS}_{\mathrm{Scr}}$ equation with the CKD-EPI $\mathrm{Scr}_{\text {equation in a }}$ retrospective study of 1312 patients and found that the performance of the Korean $\mathrm{FAS}_{\mathrm{Scr}}$ equation was equivalent to that of the CKD-EPI ${ }_{S c r}$ equation with low bias (-0.2) and high accuracy (P30 of 75.8\%, RMSE was 15.8) [20]. However, we did not find that the Korean calibrated FAS $_{\mathrm{Scr}}$ equation performed better than the primitive FAS $_{\text {Scr }}$ equation in our study of a Chinese population (bias - 10.37 vs -10.16 , IQR 21.38 vs 20.51, P30 50.4\% vs $51.4 \%$, RMSE 24.88 vs 23,82). Yong $Z$ et al first conducted a multicentre validation study comparing the FAS and CKD-EPI equations in Chinese adults and verified that the $\mathrm{FAS}_{\mathrm{Scr}-\mathrm{cysC}}$ equation performed favourably with the lowest bias (-2.87), highest precision (IQR of 19.01), highest accuracy (P30 of 74.16\%, RMSE was 17.84) and an ROC ${ }^{A U C}$ of 0.953. Furthermore, the $\mathrm{FAS}_{\mathrm{Scr}-\mathrm{cysC}}$ equation exhibited an absolute advantage in the elderly population over 60 years with the highest accuracy (P30 of 70.37\%, RMSE was 15.21)[29]. In our study, we found that the

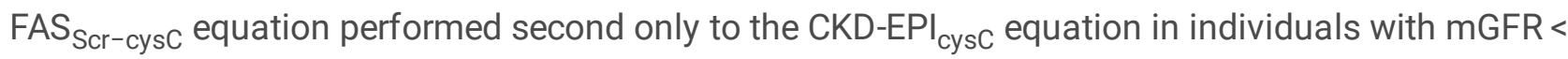
$60 \mathrm{ml} / \mathrm{min} / 1.73 \mathrm{~m}^{2}$ or adults over 70 years. However, we also obtained similar results in that the $\mathrm{FAS}_{\mathrm{Scr}-\mathrm{cysC}}$ equation performed best in all subjects and had good diagnostic accuracy. Several factors may explain the conclusion. First, the FAS equation was developed for a Caucasian population. The Q value in the FAS equation is mainly based on the characteristics of the white Belgian growth curve. The nutritional status and dietary structure of Chinese people are differentiated from those of European or American white or black individuals[30]. The ideal Q value that is applicable should match the different characteristics of the Chinese population[11]. Second, the FAS combined equation assigns $\mathrm{Scr} / \mathrm{Q}_{\mathrm{Scr}}$ and cysC/ $\mathrm{Q}_{\mathrm{cysC}}$ according to weight. The weights of the two factors in this study each account for $50 \%$. In fact, the optimal proportion of creatinine and cystatin $\mathrm{C}$ for the calculation results is not yet conclusive. However, regardless of the development of the CKD-EPI equation or FAS equation, the combination of creatinine and cystatin C could reduce the imprecision of either biomarker alone[19, 31]. Third, we found that the CKD-EPI ${ }_{\text {cysC }}$ equation obviates the race/ethnicity coefficient. However, the calibration coefficients of the various equations in the Chinese race are all greater than 1[32], and there is a paradox between them. Therefore, it is necessary to carry out multicentre and multiethnic equation verification for Chinese people.

Creatinine is produced by muscle catabolism and secretion by kidney tubular cells. Its concentration is greatly affected by the body's nutritional status and muscle mass. Poor nutritional status, infection along with an inflammatory state, or disability will affect the production of creatinine, leading to an inability to accurately assess renal function, especially between sexes. Cystatin $C$ is less affected by muscle protein content and is totally reabsorbed in the proximal tubules. The changes in the concentration of cystatin $\mathrm{C}$ are relatively stable. A 
retrospective cohort study conducted by Wang $Y$ et al with 308 patients with diabetic nephropathy in southwestern China reclassified $39 \%$ of patients with poor prognosis in CKD stages $1-2$ to CKD stages $3-5$ by the CKD-EPI cysC equation compared with the results of the $\mathrm{CKD}-\mathrm{EPI}_{\mathrm{Scr}}$ equation (the median survival of the reclassified and not reclassified groups was 52 and 94 months, respectively)[33], which indicated that the CKD-EPI cysC $_{\text {equation could }}$ sensitively detect kidney injury, especially in individuals with moderately and severely reduced GFR; the same conclusion was reached in our study. Yang $\mathrm{M}$ et al performed a retrospective study of 632 CKD patients from two general hospitals in southeastern China and verified that the cystatin C-based equation had an advantage over the creatine-based equation, especially in patients with CKD stages 3-5; the CKD-EPI ${ }_{\text {cysC }}$ equation had the lowest bias $(-4,10)$, best precision (IQR of 17.35), and best accuracy (P30 of 50.5\%, RMSE was 0.93) when GFR was < $60 \mathrm{ml} / \mathrm{min} / 1.73 \mathrm{~m}^{2}$ [34]. These results were similar to those in our study, proving the advantage of the CKD-EPI ${ }_{\text {cysC }}$ equation in Chinese individuals with moderately and severely reduced GFR. Moreover, a cohort study of 70 patients who underwent kidney transplantation conducted in Korea revealed that the ROC ${ }^{A U C}$ for cystatin $\mathrm{C}$ at the cut-off value of $45 \mathrm{ml} / \mathrm{min} / 1.73 \mathrm{~m}^{2}$ was 0.800 (that for creatinine was 0.763 ), and the best predictive value for cystatin $\mathrm{C}$ was $1.27 \mathrm{mg} / \mathrm{L}$, with a sensitivity of $77.8 \%$ and specificity of $78.8 \%[35]$. The study also showed the diagnostic advantage for the cystatin C-based equation in predicting renal function, as GFR $<45 \mathrm{ml} / \mathrm{min} / 1.73 \mathrm{~m}^{2}$ may indicate significant kidney injury among transplant recipients.

In this study, we also found that the CKD-EPI ${ }_{\text {cysC }}$ equation performed well in elderly individuals over 70 years of age. According to the law of GFR decline with age, whether GFR $<60 \mathrm{ml} / \mathrm{min} / 1.73 \mathrm{~m}^{2}$ is used as the diagnostic criterion for CKD in the elderly population is controversial, which was proposed in the BIS equation study[17]. Epidemiological studies have shown that elderly patients over 65 years old account for $53.07 \%$ of the CKD population in China[36]. A single-centre study conducted by Ye X et al among Chinese elderly CKD patients aged $\geq$ 60 years showed that the CKD-EPI ${ }_{\text {cysC }}$ equation did not perform well (bias of -9.05, IQR of 19.61, P30 of 71.74\%, RMSE was 18.50). However, the BIS-1 ${ }_{\text {Scr }}$ and BIS- ${ }_{\text {Scr - cysC }}$ equation performed better, with lower bias (-5.20 and 8.65), better precision (IQR of 21.58 and 16.31), and higher accuracy (P30 of 79.1\%, RMSE was 17.20 and 16.94) [37]. Another cross-sectional study of 218 elderly patients over 75 years of age conducted by Changjie $\mathrm{G}$ et al in southern China found that the BIS-2 ${ }_{\text {Scr-cysC }}$ equation performed best (bias of 0.63 , IQR of 4.36, P30 of $94.50 \%$,

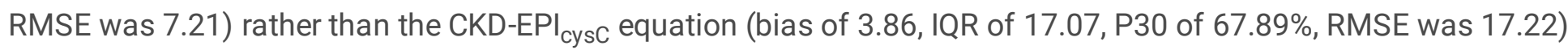
[38]. These results both showed the opposite conclusion compared to the conclusion of our study. We found that the $\mathrm{FAS}_{\mathrm{Scr} \text {-cysC }}$ equation performed equivalently to the BIS-2 ${ }_{\mathrm{Scr}-\text { cysC }}$ equation but had slightly more bias in our study. However, considering the constitution of the equation, it was convenient to use the FAS equation in clinical practice. As a special population, the elderly population often combines various complications other than nephropathy with decreases in nutritional status and immune function. For cardiovascular disease, cerebrovascular diseases, and people who take vasoactive drugs, the applicability of eGFR equations remains to be further verified.

The MDRD equation performed best among the equations based on creatinine alone in all subjects, but the accuracy was significantly lower when GFR was $<60 \mathrm{ml} / \mathrm{min} / 1.73 \mathrm{~m}^{2}$, which is consistent with the conclusion that the accuracy of the MDRD equation decreased when renal function was moderately reduced, as previously reported by Murata $\mathrm{K}$ et al. Even though the $\mathrm{CKD}_{-\mathrm{EPI}} \mathrm{Scr}_{\mathrm{r}}$ equation enhanced the specificity of the detection of GFR< $60 \mathrm{ml} / \mathrm{min} / 1.73 \mathrm{~m}^{2}$ compared with that of the MDRD Eq. (98\% vs $94 \%$ ), at the cost of reducing the sensitivity (50\% vs 70\%), the creatinine-based equation was still maligned in CKD patients [39]. The XiangYa equation is a new creatinine-based equation developed in recent years based on the central Chinese population. This equation has been externally verified in a Han population in central China and the Uighur population in western China. To our 
knowledge, we performed the first study to validate the XiangYa equation with four other main equations together in one centre. Surprisingly, we found that the XiangYa equation performed excellently in individuals with a GFR $\geq$ $60 \mathrm{ml} / \mathrm{min} / 1.73 \mathrm{~m}^{2}$ and had a good ICC value with mGFR. However, we also made a similar conclusion that it performed terribly in individuals with GFR $<60 \mathrm{ml} / \mathrm{min} / 1.73 \mathrm{~m}^{2}$ and the elderly population. This issue may be related to the original development subjects of the XiangYa equation causing significant bias, as the mean age was 52.34 with an SD of 13.23 , and the mean $\mathrm{mGFR}$ was $71.320 \mathrm{ml} / \mathrm{min} / 1.73 \mathrm{~m}^{2}$ with an SD of 23.96[21].

In this study, the accuracy P30 of each equation was found to be less than $70 \%$. This is because the plasma biochemical indexes included in this study were from 48 hours before kidney nuclear radiograph, and it was not necessarily the same result as in the morning. This was in line with the current procedures of most hospitals in China. Due to the large population in China, the imbalance between doctors and patients, and limited medical resources, biochemical blood tests and imaging examinations are often unable to be synchronized. Using biochemical test results from within 48 hours to assess renal function is not unacceptable for CKD. In recent reports, the rate of change in biomarkers was shown to be smaller than that in kidney nuclear radiography. The eGFR computed by equations is at least as reliable as the mGFR measured by nuclear medicine for monitoring patients over time[10]. The comparative verification data adopted in this study are more applicable to China's national conditions, and its statistical results have more practical clinical significance.

We verified the effect of the current popular equation on the evaluation of renal function in adult patients in central China. We must take into account the limitations of this study. First, we only enrolled Chinese Han individuals in this single-centre experiment. China is a multi-ethnic and multi-regional country. Different living customs lead to diverse human physiques, and different medical conditions contribute to inconsistent diagnoses of CKD in various regions. We will consider involve more ethnic groups in our multi-center verification research. Second, the method of assaying serum creatinine and cystatin $\mathrm{C}$ in this study may be different from those used in the derivation studies for the above equations, so was the ${ }^{99 m}$ Tc-DTPA used for mGFR measurement. Although the difference may exist in assaying equipment and materials, the current assaying level can be traced back to international certification standards, as a consequence its results are acceptable. Systematic assessment can be performed to evaluate the influence of different assaying methods on the performance of eGFR equation forward. Third, this was a retrospective validation study, and the concentration of blood biochemical indexes came from one-time testing. We were not able to evaluate the accuracy of eGFR assessed by each equation in terms of a dynamic change in renal function. Considering that the renal function of CKD patients does not change significantly in the short term, it is advisable to evaluate the calculation results of patients in hospitalization and discharging together for a comprehensive analysis in the future study.

\section{Conclusion}

The FAS equation based on the combination of Scr and cysC is considered more suitable and simpler for the Chinese population. The CKD-EPI ${ }_{\text {cysC }}$ equation is most accurate in individuals with moderately and severely reduced GFR and seniors over 70 years old. The Chinese-developed XiangYa equation is appropriate for normal or mildly injured GFR; however, its prediction accuracy still needs to be verified in individuals with moderately or severely reduced GFR and older adults.

\section{Abbreviations}


CKD: Chronic kidney disease; GFR: Glomerular filtration rate; 99mTc-DTPA: Technetium-99m-

diethylenetriaminepentaacetic acid; MDRD: Modification of Diet in Renal Disease; CKD-EPI :Chronic Kidney Disease Epidemiology Collaboration; BIS: Berlin Initiative Study; FAS: Full age spectrum; IDMS: Isotope dilution mass spectrometry; Scr: serum creatinine; cysC: Cystatin C; KDIGO: Kidney disease improving global outcomes ; IQR: Interquartile range; RMSE: Root mean square error; ICC: Intraclass correlation coefficient; ROC: Receiver-operating characteristic; AUC: Area Under the Curve.

\section{Declarations}

\section{Acknowledgements}

Thanks for the support of the department of nephrology, Imaging and clinical laboratory of Zhongnan Hospital of Wuhan University.

\section{Availability of data and materials}

The datasets analyzed during the current study are not publicly available due to the privacy of patients as well as joint ownership of research data in our institution. The data are available from the corresponding author on reasonable request, and the contact way can get through by email to xiliusa2000@126.com

\section{Authors' contributions}

SF, YGH, and XNL conceived the study and participated in the design of the study; MY, SX and SW collected the data; SF analyzed the data and drafted the manuscript; XX and YGH carried out the experiments. All authors read and approved the final manuscript.

\section{Ethics approval and consent to participate}

This study was conducted with the permission of the Ethics Committee of the

Zhongnan Hospital of Wuhan University. Written informed consent was

obtained from each subject prior to participation.

\section{Funding}

There was no funding obtained for the trial. It was performed in the Zhongnan Hospital of Wuhan University.

\section{Consent for publication}

Not applicable.

\section{Competing interests}

All the authors declare that there is no conflict of interest

\section{References}


1. Nelson RG, Grams ME, Ballew SH, Sang Y, Azizi F, Chadban SJ, Chaker L, Dunning SC, Fox C, Hirakawa Y et al: Development of Risk Prediction Equations for Incident Chronic Kidney Disease. JAMA 2019.

2. Hill NR, Fatoba ST, Oke JL, Hirst JA, O'Callaghan CA, Lasserson DS, Hobbs FD: Global Prevalence of Chronic Kidney Disease - A Systematic Review and Meta-Analysis. PLOS ONE 2016, 11(7):e158765.

3. Glassock RJ, Warnock DG, Delanaye P: The global burden of chronic kidney disease: estimates, variability and pitfalls. NAT REV NEPHROL 2017, 13(2):104-114.

4. Carrero JJ, Hecking M, Chesnaye NC, Jager KJ: Sex and gender disparities in the epidemiology and outcomes of chronic kidney disease. NAT REV NEPHROL 2018, 14(3):151-164.

5. Blaufox MD, Aurell M, Bubeck B, Fommei E, Piepsz A, Russell C, Taylor A, Thomsen HS, Volterrani D: Report of the Radionuclides in Nephrourology Committee on renal clearance. J NUCL MED 1996, 37(11):1883-1890.

6. Inoue Y, Itoh H, Tagami H, Miyatake H, Asano Y: Measurement of Renal Depth in Dynamic Renal Scintigraphy Using Ultralow-Dose CT. CLIN NUCL MED 2016, 41(6):434-441.

7. Ebert N, Koep C, Schwarz K, Martus P, Mielke N, Bartel J, Kuhlmann M, Gaedeke J, Toelle M, van der Giet M et al: Beta Trace Protein does not outperform Creatinine and Cystatin $\mathrm{C}$ in estimating Glomerular Filtration Rate in Older Adults. Sci Rep 2017, 7(1):12656.

8. Waheed S, Matsushita K, Astor BC, Hoogeveen RC, Ballantyne C, Coresh J: Combined association of creatinine, albuminuria, and cystatin $\mathrm{C}$ with all-cause mortality and cardiovascular and kidney outcomes. Clin J Am SoC Nephrol 2013, 8(3):434-442.

9. Hu Y, Liu H, Du L, Wan J, Li X: Serum Cystatin C Predicts AKI and the Prognosis of Patients in Coronary Care Unit: a Prospective, Observational Study. Kidney Blood Press Res 2017, 42(6):961-973.

10. Rowe C, Sitch AJ, Barratt J, Brettell EA, Cockwell P, Dalton RN, Deeks JJ, Eaglestone G, Pellatt-Higgins T, Kalra PA et al: Biological variation of measured and estimated glomerular filtration rate in patients with chronic kidney disease. KIDNEY INT 2019, 96(2):429-435.

11. Ma YC, Zuo L, Chen L, Su ZM, Meng S, Li JJ, Zhang CL, Wang HY: Distribution of measured GFR in apparently healthy Chinese adults. AM J KIDNEY DIS 2010, 56(2):420-421.

12. Grubb A, Blirup-Jensen S, Lindstrom V, Schmidt C, Althaus $H$, Zegers I: First certified reference material for cystatin C in human serum ERM-DA471/IFCC. CLIN CHEM LAB MED 2010, 48(11):1619-1621.

13. Myers GL, Miller WG, Coresh J, Fleming J, Greenberg N, Greene T, Hostetter T, Levey AS, Panteghini M, Welch M et al: Recommendations for improving serum creatinine measurement: a report from the Laboratory Working Group of the National Kidney Disease Education Program. CLIN CHEM 2006, 52(1):5-18.

14. Levey AS, Coresh J, Greene T, Marsh J, Stevens LA, Kusek JW, Van Lente F: Expressing the Modification of Diet in Renal Disease Study Equation for Estimating Glomerular Filtration Rate with Standardized Serum Creatinine Values. CLIN CHEM 2007, 53(4):766-772.

15. KDIGO 2012 Clinical Practice Guideline for the Evaluation and Management of Chronic Kidney Disease. KIDNEY INT SUPPL 2013, 3(1):1-150.

16. Stevens LA, Claybon MA, Schmid CH, Chen J, Horio M, Imai E, Nelson RG, Van Deventer M, Wang HY, Zuo L et al: Evaluation of the CKD-EPI Equation in Multiple Races and Ethnicities. KIDNEY INT 2011, 79(5):555-562.

17. Schaeffner ES, Ebert N, Delanaye P, Frei U, Gaedeke J, Jakob O, Kuhlmann MK, Schuchardt M, Tolle M, Ziebig R et al: Two novel equations to estimate kidney function in persons aged 70 years or older. ANN INTERN MED 2012, 157(7):471-481. 
18. Pottel H, Hoste L, Dubourg L, Ebert N, Schaeffner E, Eriksen BO, Melsom T, Lamb EJ, Rule AD, Turner ST et al: An estimated glomerular filtration rate equation for the full age spectrum. Nephrol Dial Transplant 2016, 31(5):798-806.

19. Pottel H, Delanaye P, Schaeffner E, Dubourg L, Eriksen BO, Melsom T, Lamb EJ, Rule AD, Turner ST, Glassock RJ et al: Estimating glomerular filtration rate for the full age spectrum from serum creatinine and cystatin $\mathrm{C}$. Nephrol Dial Transplant 2017, 32(3):497-507.

20. Jeong TD, Cho EJ, Lee W, Chun S, Hong KS, Min WK: Accuracy Assessment of Five Equations Used for Estimating the Glomerular Filtration Rate in Korean Adults. ANN LAB MED 2017, 37(5):371-380.

21. Li DY, Yin WJ, Yi YH, Zhang BK, Zhao J, Zhu CN, Ma RR, Zhou LY, Xie YL, Wang JL et al: Development and validation of a more accurate estimating equation for glomerular filtration rate in a Chinese population. KIDNEY INT 2019, 95(3):636-646.

22. Blirup-Jensen S, Grubb A, Lindstrom V, Schmidt C, Althaus H: Standardization of Cystatin C: development of primary and secondary reference preparations. Scand J Clin Lab Invest Supp/ 2008, 241:67-70.

23. Gates GF: Split renal function testing using Tc-99m DTPA. A rapid technique for determining differential glomerular filtration. CLIN NUCL MED 1983, 8(9):400-407.

24. KJDOQI Clinical Practice Guidelines for Chronic Kidney Disease: Evaluation,Classification,and Stratification. AM J KIDNEY DIS 2002, 39(2):S17-S31.

25. Lv JC, Zhang LX: Prevalence and Disease Burden of Chronic Kidney Disease. ADV EXP MED BIOL 2019, 1165:315.

26. Pottel H, Hoste L, Yayo E, Delanaye P: Glomerular Filtration Rate in Healthy Living Potential Kidney Donors: A Meta-Analysis Supporting the Construction of the Full Age Spectrum Equation. NEPHRON2017, 135(2):105119.

27. Chai L, Wang M, Cai K, Luo Q, Yi H, Wu J: Full age spectrum equation may be an alternative method to estimate the glomerular filtration rate in Chinese patients with chronic kidney disease. CLIN NEPHROL 2018, 89(6):413421.

28. Xie P, Li HL, Huang JM, Wei LG: Validation of the full-age spectrum equation in the approximation of glomerular filtration rate in Chinese patients with chronic kidney disease. Ren Fail 2019, 41(1):467-472.

29. Yong Z, Li F, Pei X, Liu X, Song D, Zhang X, Zhao W: A comparison between 2017 FAS and 2012 CKD-EPI equations: a multi-center validation study in Chinese adult population. INT UROL NEPHROL 2019, 51(1):139146.

30. Wulan SN, Westerterp KR, Plasqui G: Ethnic differences in body composition and the associated metabolic profile: a comparative study between Asians and Caucasians. MATURITAS 2010, 65(4):315-319.

31. Inker LA, Schmid CH, Tighiouart H, Eckfeldt JH, Feldman HI, Greene T, Kusek JW, Manzi J, Van Lente F, Zhang $\mathrm{YL}$ et al: Estimating glomerular filtration rate from serum creatinine and cystatin C. N Eng/ J Med 2012, 367(1):20-29.

32. Teo BW, Zhang L, Guh JY, Tang S, Jha V, Kang DH, Tanchanco R, Hooi LS, Praditpornsilpa K, Kong X et al: Glomerular Filtration Rates in Asians. Adv Chronic Kidney Dis 2018, 25(1):41-48.

33. Wang Y, Zhang J, Teng G, Wu Y, Han Q, Li H, Wang T, Liu F: Comparison of Performance of Equations for Estimated Glomerular Filtration Rate in Chinese Patients with Biopsy-Proven Diabetic Nephropathy. DIS MARKERS 2019, 2019. 
34. Yang M, Xu G, Ling L, Niu J, Lu T, Du X, Gu Y: Performance of the creatinine and cystatin C-based equations for estimation of GFR in Chinese patients with chronic kidney disease. CLIN EXP NEPHROL 2017, 21(2):236-246.

35. Yang Y, Kim KY, Hwang I, Yim T, Do W, Kim MJ, Lee S, Jung HY, Choi JY, Park SH et al: Cystatin C-Based Equation for Predicting the Glomerular Filtration Rate in Kidney Transplant Recipients. Transplant Proc 2017, 49(5):1018-1022.

36. Liu BC, Wu XC, Wang YL, Wang B, Gao J, Zhang QJ, Zhu Y, Zhang XL, Yin LF: Investigation of the prevalence of CKD in 13,383 Chinese hospitalised adult patients. CLIN CHIM ACTA 2008, 387(1-2):128-132.

37. Ye X, Wei L, Pei X, Zhu B, Wu J, Zhao W: Application of creatinine- and/or cystatin C-based glomerular filtration rate estimation equations in elderly Chinese. CLIN INTERV AGING 2014, 9:1539-1549.

38. Changjie G, Xusheng Z, Feng H, Shuguang Q, Jianwen L, Junzhou F: Evaluation of glomerular filtration rate by different equations in Chinese elderly with chronic kidney disease. INT UROL NEPHROL 2017, 49(1):133-141.

39. Murata K, Baumann NA, Saenger AK, Larson TS, Rule AD, Lieske JC: Relative performance of the MDRD and CKD-EPI equations for estimating glomerular filtration rate among patients with varied clinical presentations. Clin J Am Soc Nephrol 2011, 6(8):1963-1972.

\section{Figures}

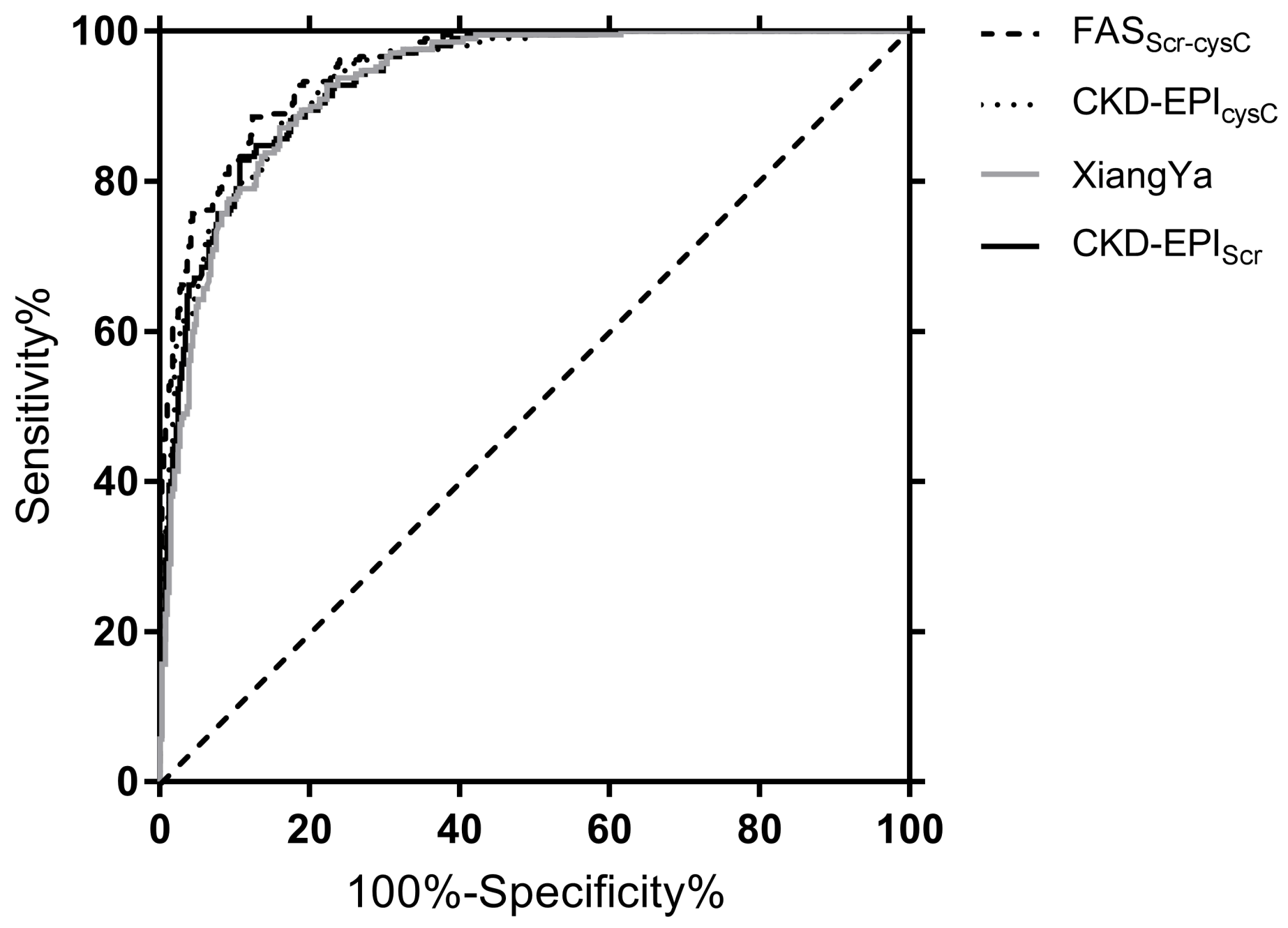


Figure 1

The ROC curve of equations for diagnose CKD in all subjects
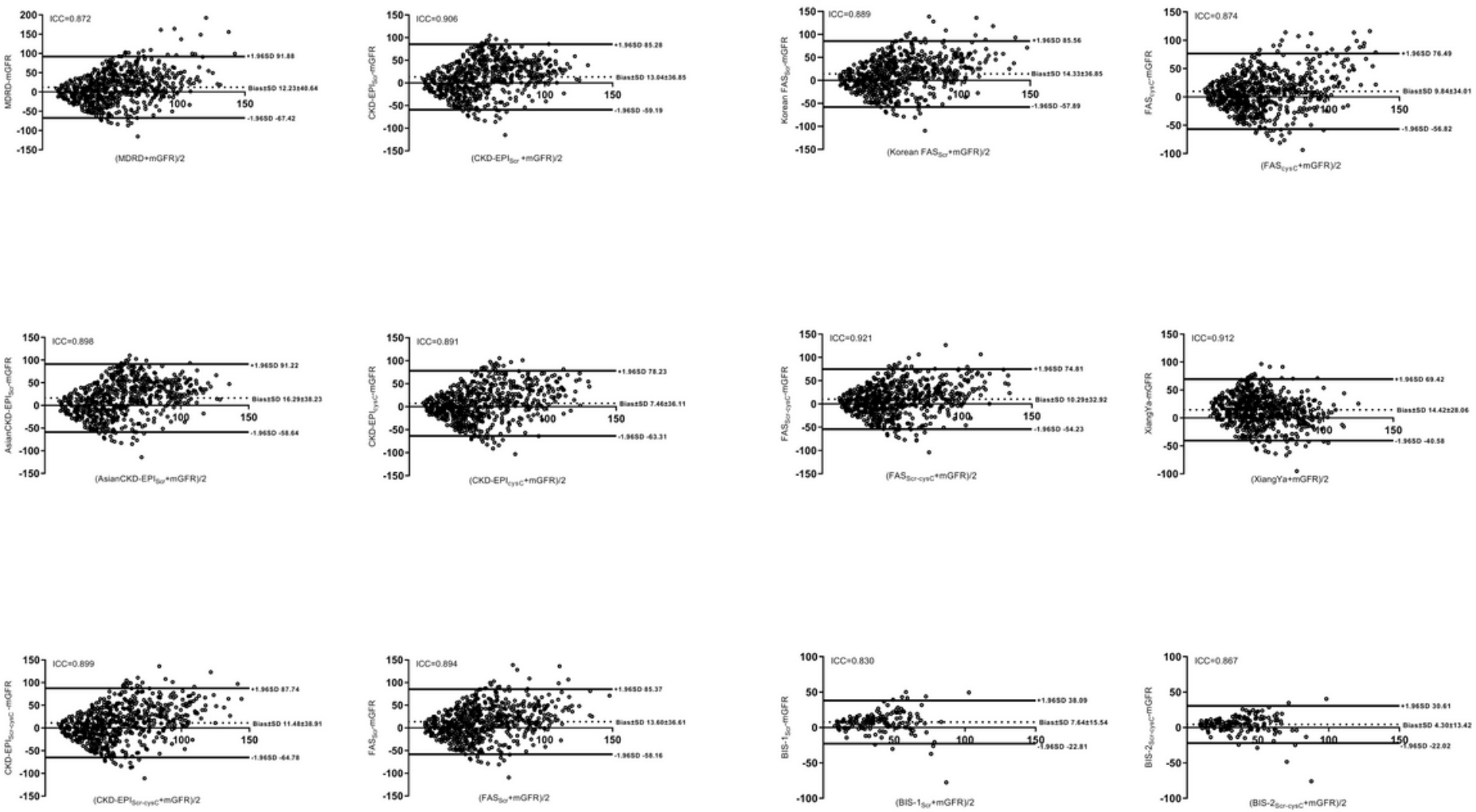

Figure 2

The Bland-Altman plot of comparision between eGFR and mGFR 